\title{
Study and Analysis of the Current Situation of Students' Oral English in Medical Colleges and its Countermeasures
}

\author{
Yuan Kong* \\ Jining Medical University \\ Jining, China
}

\author{
Jie Jiang \\ Jining Medical University \\ Jining, China
}

\begin{abstract}
This paper aims to show up the present situation of oral English in the contemporary students of medical majors, explores the causes of its formation and proposes strategies to enhance oral ability of students of medical majors. We do a survey to 368 medical majors' undergraduates who come from five medical colleges in Shandong province, including 137 male students and 231 female students. This study adopts the way of questionnaire survey and interviews to search for data. The way of composing questionnaire construction uses Likert Scale, using SPSS 2.0 software to analyze data. According to data, $70 \%$ of the students believe that they don't have a good command of solid foundation in oral English and are not enthusiastic to learn. The data the team has collected have veracity and validity and objectively reflect real situation of students. In the meanwhile, the article has a few limitations to some extent because size of the sample isn't very vast. In the face of these problems of oral studying and teaching, students should focus on the accumulation of basic knowledge and acquisition of communicative strategies, teachers should alter teaching methods and implement accurate teaching, school should create an active atmosphere of learning, educational department should improve the evaluative system of teaching and introduce oral test. These suggestions can contribute to enhancement of oral ability for students of medical majors, improvement of teachers' teaching level, the realization of the elite education, satisfaction of the social needs, and designation of English policy.
\end{abstract}

Keywords-medical majors' collegiate students; oral English; analysis of the current situation; countermeasures

\section{INTRODUCTION}

The 21st century is a new era of China's opening to the outside world. As early as 2010, China had become the second largest economy in the world. In terms of trade, China is now the leading partner of nearly 120 countries and regions in the world. At the same time, the global constructional project is steadily progressing; in-depth development continuously upgrades the national transformation of economic structure.

This paper is sponsored by A Project of Shandong Province Higher Educational Humanities and Social Sciences Research (J17RA054); Social Science Planning Research Program of Shandong Province (17CWZJ38); College Students' Innovative Training Project of Jining Medical Un iversity (cx2017052); Scientific Research Project of College Students in Jining Medical University (JYXS2017RW017); Research Program of Young Teachers' Education and Teaching of Shandong Province (16SDJ232); Youth and Adolescents Quality Education Work Planning Program of Shandong Province (13AJY090); Scientific Research Program of Jining Medical University (JY2013RW032); An Industry-University Cooperative Project of Ministry of Education; The Visiting Scholar Funded Program of Young Backbone Teachers in Jining Medical University
The G20 summit of Hangzhou, the Brics leaders' meeting in Xiamen and other major international conferences and events were held in our country. All of these have led to an increasing demand from all sectors of our society for high level's comprehensive application-oriented talents who are proficient in professional knowledge and have certain expressive ability of English. As a contemporary collegiate student, after graduating, the ability of oral expression of English has a prominent role in social work and communication. The ability to communicate fluently with foreign colleagues and friends in English is an important criterion for society how to evaluate their value. Therefore, the importance of cultivating the ability to speak native English for non-English majors' students is worthy of our wide attention.

To this end, the author in Shandong province for medical major students' ability of oral English Sums up analysis of the present situation of the investigation, so that we can have a chance and method to explore its causes and come up with the training strategies which are solid, contribute to sufficient enhancement of oral ability and get access to promote ability of ascension of oral English for undergraduate collegiate students of medical major. So as to bring about Classing for ability of independent culture about the students' oral English, the improvement of teachers' teaching level in English classroom of teaching, the university of the realization of the elite education, the development the society itself needs to be satisfied with. What has been illustrated above also provides an effective reference for those who are in charge of the power to design English policy[1].

\section{RESEARCH DESIGN}

The group of project focuses on undergraduate students of colleges and universities. In Shandong province we do a survey to 368 medical majors' undergraduates, including 137 male students and 231 female students. With an average age of 19, entrance is received before 6 to 9 years of English education. Therefore, it can objectively reflect the current situation of the ability of students' oral English about collegiate medical majors This study adopts the way of questionnaire survey and interviews to search for data which is relative to oral ability of collegiate students. The way of composing questionnaire construction uses Likert scale whose options include don't agree, basically don't agree, uncertain, basically agree, and fully agree. Every option has respectively the corresponding 
score of 1-5 points. The team puts out 368 questionnaires and recycles 359 effective questionnaires; effective rate of questionnaires was $97.6 \%$. A random sample of students surveyed for 20 people have been asked to make a valid interview in order to guarantee the veracity and validity of our research.

\section{A. Analysis and Causes of Collegiate Students' Oral English}

Team of the project, according to the investigation and the collected data, combines with the content of the interview counseling. As for the reality and problems of college students' ability of oral English about the contemporary medical majors, we traced back its reasons and make an inductive reflection basing on the results of questionnaire and interview consultation. It is concluded that the following views.

1) Students do not have a solid foundation in oral English and are not enthusiastic to learn

As a language, the improvement of English requires continuous accumulation and practice. As an output stage of English learning, oral English is largely influenced by learners' basic knowledge of English. According to the survey's results, 70 percent of the students believe that they do not have a good command of the key knowledge of oral practice, such as vocabulary, grammar, phonetics and tone. As the saying goes, 'the foundation is not strong, the earth is shaking". This also is suitable for students who are learning spoken English. Students' oral English is not fluent, which has something to do with collegiate students' reserve of vocabulary, phrases and examples. As the basis of English learning, without the accumulation of rich vocabulary and phrases, it is difficult to express even a beautiful language, also will lead to the failure of words to convey meaning and have a dry expression. In addition, students are not familiar with or misread English phonetic symbols, which leads to inaccurate pronunciation of words. As a result, the number of words recognized keeps increasing and the number of words misread also gradually increases. For some students, in the process of learning, the expression of mastering wrong re-read, even totally erroneous reading which makes the language's rhythm disorder. Consequently, a non uniform and syllable problem comes into being quickly, which turns out to the inaccuracy of expression of the contents when learners start to make a communication. In addition, only $18 \%$ of the students had plans about oral practice and planned practice. At the same time, 63 percent of the students seldom practice spoken English and only practice before the exam. The comparison between the two shows that students' slackness in oral English's study and their low enthusiasm for oral English study are the fundamental reasons that hinder the improvement of ability of oral English about collegiate students.

2) The learning atmosphere of oral English is not strong and the learning method is simple

Frequently using English to talk and communicate can promote the improvement of spoken English. Therefore, the degree of cultural atmosphere of strong English in the environment of learners has an important influence on the improvement of their oral English. According to the survey's results, $80 \%$ of students seldom use English while communicating with classmates and friends in daily life.
Seventy-two percent of students have hardly ever participated in English competitions of speaking, competitions of debating, English clubs and other activities. It can be seen that there is a lack of opportunities for students of middle school to practice speaking English in their spare time. That caused the lack of the environmental atmosphere of oral English among the students after school. That is not a positive learning environment, doesn't like that the native students of learning English are exposed in circumstance of whole English. Thus current environment can't improve the level of students' oral English universally. In addition, we also can find ineffective and improper learning methods. The lack of diversity of oral English and almost do not take part in relevant activities or organizations, which make their learning form be limited to reading English articles. Thus students are unable to get a approach of the real English communication in the process of making a hand of communicational skills of a kind of language and learning intensely. Eventually that leads to studying process which is boring and dull, learning interest which disappears gradually.

3) The teaching and examinatorial system of oral English is not perfect and the level of teachers' oral English needs to be improved.

The cultivation of collegiate students' ability of oral English not just relies on the student's own learning literacy and autonomous learning ability of ascension. The pros and cons of teaching, examinatorial mode and the level of teacher's teaching to the raising of students' oral English ability also play an important role. The results of the survey shows that $75 \%$ of students desire to improve their expressional ability of oral English. On the contrary, 82\% of students think that in English classroom teaching content set has smaller usage to the promotion of their own ability of practicing spoken English. With regard to the two, the asymmetric relationship between them shows in the traditional teaching model of collegiate English, which centers on CET and pays attention to cultivate the students' reading, writing, listening, translational course. That already can't satisfy the need of the students, also reflects teaching system of the collegiate English which is necessary to innovate. Another 75 percent want English teachers to teach in English. This shows that teachers still use their native tongue as the main language of teaching in English class. On the other hand, it shows that students are not satisfied with the monotonous learning environment and have higher requirements for the linguistic environment in class. At the same time, it also puts forward higher requirements for the level of teachers' oral English. Finally, although 72 percent of students believe that fluency and standard of spoken English are important for future development. However, only 18 percent of the students have oral practical plans and practice in a planned way. This shows that students do not have enough motivation to learn and their enthusiasm for learning needs to be further improved. However, spoken English as a contact with the professional knowledge is not very close. Students of medical majors don't have a lot of willing to spend a great amount of times on spoken English and accumulating essential knowledge. The test of four and six levels of English for medical majors' collegiate students has a slight attention to choose to learn content which is closely related to oral English. Only by cultivating the students' interest in learning can it 
increase the enthusiasm of study. It puts an immense influence on stepping up the ability that students speak with English. So the examinatorial system of perfect English to improve collegiate students' oral expressional ability plays a key role.

In addition, under the influence of traditional teaching, the current situation of collegiate students' learning of extracurricular English is basically disordered. Most students only rely on interest or pressure to study outside the classroom. To the extent, they have strong randomness, blindness and lack of systematic planning and clear goals. Especially for freshmen and sophomores, they often study in a muddled way. Many domestic scholars have found through analysis that the lack of learning strategies is one of the main reasons for this situation. Teachers found in teaching practice that extracurricular learning atmosphere, abundant studying information or source, learning equipment, and technical guidance, which also make a significant function to foster the ability of speaking English well. Such as the lack of resources is also one important factor that affects collegiate students' performance whether good or bad in the course of English learning outside the classroom. Therefore, in order to promote the formation of personalized learning methods and the improvement of independent learning ability of students, teachers should also change the teaching mode and guiding methods. Teachers can adopt the kind of teaching mode that teacher distribute learning task to students according to the students' learning ability of English and according to the different performance of high and low, then teacher divide students into different learning group. For one thing, the students are able to complete the linguistic activities in the form of task. For another, teacher can let the regimental members under extracurricular cooperation to complete task of different level. According to the statistical analysis, using the way which combines the formative evaluation with summative evaluation ensures a real and objective reflection to the learning of the students. In the meanwhile this also can help students to understand their own learning and improve the students' learning autonomy, so as to improve students' comprehensive ability of applying English. Furthermore, according to different teaching conditions, teachers can adjust the evaluative ratio and adopt different evaluative methods to promote students' independent learning. In the process of teaching, teachers can improve students' autonomous ability by means of discussion, answering questions and quizzes. At the same time, the assignment of tasks can also be carried out according to the individual condition. According to the aptitude of teaching strategy, it will not only increase students' studying time and opportunities in extracurricular study. It is also convenient for teachers to monitor and guide students' independent learning after class. Teachers should also give appropriate assignments of homework to students who have poor basic knowledge and are in possession of less motivation to learn.

\section{B. Ways and Methods to Improve Collegiate Students' Ability of Oral English}

In today's global economic integration, China's economic and cultural output is taking on growing tendency. Social economic development of our country right now for collegiate students' ability of medical majors of oral English put forward higher requirements. The cultivation of ability of oral English for the medical majors' collegiate students is not only the weak link in English teaching of college in China, but also is difficult to practice in the process of students' learning of collegiate English and mastering its essential content. In 2007 national ministry of education designs the new developmental root that is named as "requirements of curriculum of collegiate English". The policy not only puts forward to improve the students' autonomous learning ability but also considers the development of autonomous learning ability of collegiate students. The transformation of English teaching model is an important factor of successive education of collegiate English. Therefore, it is necessary to attach more attention to cultivate students' ability of independent learning of extracurricular English. However, the team of the project through the investigation and interview gradually realize that between the current ability of students' oral English and the ministry of education promulgated " curricular requirements of collegiate English (trial)" that means "using fluent English between general topics of conversation, expressing personal opinions, feelings, the basic point of view, etc, stating basic the facts, reasons and describing events clearly, gaining a mastery of comparatively correct pronunciation and intonation." [1], there is a clear gap in the survey. Therefore, team of the project combined the survey and interview to explore the improvement of collegiate students' oral ability for medical majors. The followings are several recommendations about how resolve those problems has been described above.

1) Focus on the accumulation of basic knowledge and acquisition of communicative strategies.

Learning and improvement of oral English is a gradual process. In order to practice oral English well, learners should at the first reserve a certain amount of words, phrases and classic American sentences and master basic grammatical rules As you accumulate this basic knowledge, you should also learn to use certain methods such as using the memorial method of associating root and affix while students memorize words, reciting and making the grammatical structural analysis and summarizing on some classic sentences, memorizing grammatical rules and some relative fixed contact. In the same way, the words, phrases and sentences have been memorized should be timely reviewed, that can also improve their proficiency and promote ability of expressing point fluently in English. Of course, it is not enough to master a large number of vocabulary, phrases and grammatical rules for completing the elegant oral expression. In this process, we should also strengthen the study of pronunciation and intonation, which is the key to good oral English. In the process of cultivating correct pronunciation and intonation, above of all students can learn basic phonetic symbols through online resources or by purchasing relevant books. It lays a solid foundation for accurate pronunciation of words. Furthermore, the coherence of English expression can be improved through listening, writing and reading. Last but not least, the natural degree of pronunciation can be improved by imitating the tone of radio station or news' anchor.

In addition, the reasonable use of communicative strategies also plays an important role in improving ability of students' oral. As English is a foreign language, students often inevitably 
encounter difficult expressive situations in the process of communication. In this case, students should adopt reasonable strategies, such as "strategy of asking question, strategy of adjusting, strategy of temporary construction, roundabout strategy, etc." [2], so as to ensure the smooth progress of the conversation.

2) Improve teachers' quality, improve teaching methods and implement accurate teaching

The oral English level of English teachers plays a vital role in the development of expressionistic ability of students' English. In the process of teaching, the teacher should improve their pronunciation and intonation, adjust speed, give students establish good linguistic standard, and to arouse students' interest in expressing opinions in English, improve their learning enthusiasm. Secondly, teachers should improve their teaching methods and increase the participation of students in classroom's teaching. In English class, the teacher is a commander and the student is the classroom's main body. The teacher should give the student more opportunities to speak English, especially those students are provided with poor basic of the English. In the design of classroom's activities, teachers can share the audio-visual materials which are relative to teaching content with students to promote their audio-visual ability. They can also create a linguistic atmosphere by oral transmission, tongue twisters, and playing English songs a few minutes before class. In addition, the students' uneven level of oral English makes teachers unable to design a reasonable teaching plan, and it is difficult for students to improve their learning efficiency. Therefore, according to the students' the level of oral English, they can divide students into different levels, design the corresponding linguistic environment, and teach different levels' students with respective teaching way, so that students can improve their ability of oral English more comprehensively and efficiently. In addition, collegiate students generally exist in several problems such as insufficient learning plans, insufficient self-assessment, and inability to learn and using English through multiple channels. Due to the inefficiency of teaching in class, collegiate students cannot fully acquire the ability to apply English through short classroom learning, which demands students to carry out independent learning after class [3]. In extracurricular learning of English, students should learn independently according to the requirements of teachers. For example: the teacher should let students who are in possession of the poor linguistic ability of English know their level of English is low and realize that they need to make up for the lack of basic knowledge of English as soon as possible. Then they should select appropriate texts and practice, develop good studying plan and self-study on schedule after class.

3) Expand the learning mode and create an atmosphere of independent learning

Due to the limitation of teaching time in class, teachers do not play a significant role in improving students' ability of oral English. Therefore, the key to the improvement of students' oral expressionistic ability lies in their learning of oral English after class. We should actively respond to the national policies and regulations, encourage collegiate students to strengthen the ability of independent learning and actively create a concept of comprehensive learning, lifelong learning. In addition, the students' English learning after class cannot leave the parents' support and encouragement. After leaving the classroom, the students keep away from the sight of the teacher, lack of the guidance of teachers and optimistic learning conditions. So parents need to urge students to complete self-learning appropriately. In holiday of summer and winter every year, parents can also encourage their children to communicate with native English-speaking foreigners for some time. Moreover, there are many famous English training institutions in China. Students can improve level of their English according to their own interest or according to their own weaknesses of English at there. At the same time, the rapid development of Internet technology has also changed the learning way of oral English [4]. After class, students use the browser to collect learning materials, visit websites to watch English video, and participate in online courses. They can also use their mobile phone to download the APP. For example, fluently speaking English, interesting English dubbing, scallop oral English, etc. Students can go on with Online or offline learning and communicating with English. You can also follow WeChat's public accounts and micro-bloggers to learn the skills of oral English and listen to the latest English news. In the real learning of spoken English, students also should contact the real linguistic environment, immerse in English atmosphere as much as possible. Their speaking ability will be improved in the osmosis by the way. At the same time, the communicative strategy will also be consolidated. Schools should provide students with a more perfect learning environment after school [5]. Colleges and universities should consciously create an atmosphere for independent learning of English within the school. This requires the relevant departments of the school to organize and mobilize to a certain extent. Based on the existing English, these activities need close to the student's life, are suitable for the level of students' English. These activities range over society, western cultural knowledge, customs and ideas, gradually improve the students' actively participation. In addition, these activities should be properly held so that more students can participate in it. These programs and methods of the activities are flexible, colorful and can form part of the school's extracurricular activities [6]. For example: On the teaching platform of network resources, students can see Internet curriculum about English's learning. The school may establish chat room of English to let the students practice oral English as well. At the same time, School can set up an English corner which takes place thematic activities on a regular basis. School also holds regularly English singing competition, English speech contest, encourages students to set up community of oral English, organizes oral training, sets up FM stations of campus English or studio and periodically broadcast English hearing, etc. Students immerse in a variety of learning forms of spoken English for a long time. Finally students will find suitable approach to learn oral English. Students to learn English won't feel boring and shady. These methods also will improve their learning autonomy [7].

In addition, learning of extra-curricular English is an important part of English learning of collegiate students which is the extension and expansion of traditional classroom's teaching as well as the deepening and development of classroom's learning. At present, the number of English courses for medical majors in China is small and students have no time 
to review and practice after class, which is far from meeting the requirements of linguistic learning [8]. Teaching mode of collegiate English which does not include extra-curricular learning is not a complete teaching mode. In order to make up for the deficiency of traditional teaching of classroom, collegiate teachers should encourage students to conduct learning of extracurricular English and extensive communication.

4) Improve the evaluative system of teaching and introduce oral test

English is a compulsory basic course for students in colleges and universities and its examinations and assessments relatively are improving day by day [9]. Among them, oral test relies on advanced science and technology in order to become concise, efficient and accurate. It has been proved by practice that the introduction of oral test in examination of collegiate English can promote the improvement of the level of teachers' oral teaching and the ability of students' oral learning. In the test of oral English, Designer of the test can draw lessons from the experience of band 4 and band 6 of the collegiate English test. Teachers can assess comprehensively students' recording of spoken English [10]. In addition, teachers can also use classroom's questions to evaluate students' level of oral English and record their scores into their final score of oral English with sectional proportion. At the same time, under the supervision of oral test, students' initiation and enthusiasm for oral practice will also increase.

\section{CONCLUSION}

Acquisition of oral English is the sublimation of the learning mode of traditional English, which has high requirements on ability of teachers' teaching and foundation of students' English. In the current English learning of medical college, the student has memory of English vocabulary and grammatical rules. But in practical application and communication, they often appear embarrassed, are unable to understand or dare not to speak. Therefore, the collegiate students' confidence and enthusiasm in English learning are gradually weakened, which is not conducive to the cultivation and development of students' ability of comprehensive application. Under the background of the new education, teacher's level of spoken English needs to keep up with students' learning condition. At the same time, teachers also should reform old-fashioned teaching way in the light of learning level of students' oral English. In terms of their aptitude, teacher need carry out precise teaching. Thereby the students' efficiency of linguistic input can be improved solidly. In addition, learning spoken English requires learners to spend more time and energy on a large number of frequent linguistic practices. It also requires that students should constantly learn and consolidate basic knowledge, overcome the learning mood of anxiety, make full use of learning resources of network, take an active part in English activities, enrich linguistic surroundings. Only in this way can students put what they have learned into practice and improve their communicative skills of English so as to keep up with the trend of epoch.

\section{REFERENCES}

[1] Department of higher education, Teaching requirements for colleg iate English courses, Shanghai: Shanghai foreign language about education press, 2007.

[2] X. L. Zhou, English communicative strategy, Suzhou University Press, 2012.

[3] M. L. Li, L. Liu, "Exploration and practice of educational innovation and entrepreneurship in local medical colleges", Research and practice of education in medicine, 2017, No.1, pp. 1-3.

[4] J. M. Han, X. J. Wang, "Research on the current situation of colleg iate students' oral English in non-english majors", Vision of Science and technology, 2016, No.6, pp. 74.

[5] J. L. Jiao, "Existing problems and improved directions of innovative training programs for collegiate students", Northwest medicine education, 2016, No.1, pp. 10-12.

[6] X. M. Sun, "Research on learning adaptability of medical undergraduates and its influencing factors", Education, 2016, No.3, pp. 425-428.

[7] Y. R. Hu, "Exploration on the thinking cultivation model of Chinese medicine for overseas students in China", Education, 2016, No.4, pp. 620-623.

[8] X. L. He, "Research progress of clinical ability and evaluative methods for medical students", Northwestern medicine education, 2016, No.4, pp. 523-526.

[9] P. Chen, "Teacher factors and countermeasures influencing bilingual teaching effect of traditional Chinese medicine" Research and practice of medical education, 2017, No.3, pp. 397-399.

[10] W. T. Zhuang, X. T. zhang, "Comparative analysis of teaching effect between English and Chinese in Shantou university medical college", Research and practice of medical education, 2017, No.6, pp. 912-915. 